Archived version from NCDOCKS Institutional Repository http://libres.uncg.edu/ir/asu/

\title{
Appalachỉan
}

B O O N , NORTH CAROL I N A

\section{Tracing Impacts Of Partner Abundance In Facultative Pollination Mutualisms: From Individuals To Populations}

\author{
By: Jennifer Geib and Candace Galen
}

\begin{abstract}
Partner abundance affects costs and benefits in obligate mutualisms, but its role in facultative partnerships is less clear. We address this gap in a pollination web consisting of two clovers (Trifolium) that differ in specialization on a bumble bee pollinator Bombus balteatus. We examine how pollination niche breadth affects plant responses to pollinator abundance, comparing early - flowering (specialized) and late - flowering (generalized) cohorts of T. parryi and early T. parryi to T. dasyphyllum, a pollination generalist. Co - pollinators disrupt the link between B. balteatus visitation and pollination rate for both clovers. Only for early - flowering T. parryi do visitation, pollination, and seed set increase with density of B. balteatus. Bumble bee density also alters timing of seed germination in T. parryi, with seeds from plants receiving augmented B. balteatus germinating sooner than seeds of open - pollinated counterparts. Benefits saturate at intermediate bumble bee densities. Despite strong effects of B. balteatus density on individual plant fitness components, population models suggest little impact of B. balteatus density on $\lambda$ in T. parryi or T. dasyphyllum. Findings show that functional redundancy in a pollinator guild mediates host - plant responses to partner density. Unexpected effects of pollinator density on life history schedule have implications for recruitment under pollinator decline.
\end{abstract}

Geib, J.C. and Galen, C. (2012), Tracing impacts of partner abundance in facultative pollination mutualisms: from individuals to populations. Ecology, 93: 1581-1592. https://doi.org/10.1890/11-1271.1. Publisher version of record available at: https://esajournals.onlinelibrary.wiley.com/doi/10.1890/11-1271.1 


\title{
Tracing impacts of partner abundance in facultative pollination mutualisms: from individuals to populations
}

\author{
JenNifer C. GeiB ${ }^{1,3}$ and Candace Galen ${ }^{2}$ \\ ${ }^{1}$ Biology Department, 572 Rivers Street, Appalachian State University, Boone, North Carolina 28608 USA \\ ${ }^{2}$ Division of Biological Sciences, 105 Tucker Hall, University of Missouri, Columbia, Missouri 65211 USA
}

\begin{abstract}
Partner abundance affects costs and benefits in obligate mutualisms, but its role in facultative partnerships is less clear. We address this gap in a pollination web consisting of two clovers (Trifolium) that differ in specialization on a bumble bee pollinator Bombus balteatus. We examine how pollination niche breadth affects plant responses to pollinator abundance, comparing early-flowering (specialized) and late-flowering (generalized) cohorts of $T$. parryi and early $T$. parryi to $T$. dasyphyllum, a pollination generalist. Co-pollinators disrupt the link between $B$. balteatus visitation and pollination rate for both clovers. Only for earlyflowering $T$. parryi do visitation, pollination, and seed set increase with density of $B$. balteatus. Bumble bee density also alters timing of seed germination in $T$. parryi, with seeds from plants receiving augmented $B$. balteatus germinating sooner than seeds of open-pollinated counterparts. Benefits saturate at intermediate bumble bee densities. Despite strong effects of $B$. balteatus density on individual plant fitness components, population models suggest little impact of $B$. balteatus density on $\lambda$ in $T$. parryi or $T$. dasyphyllum. Findings show that functional redundancy in a pollinator guild mediates host-plant responses to partner density. Unexpected effects of pollinator density on life history schedule have implications for recruitment under pollinator decline.
\end{abstract}

Key words: alpine clover; Bombus balteatus; density dependence; facultative; mutualism; pollination; pollination niche; specialization; Trifolium dasyphyllum; Trifolium parryi.

\section{INTRODUCTION}

Mutualisms benefit interspecific partners, yet realized benefits depend on biotic and abiotic environmental factors (Bronstein 1994). Partner abundance is an intrinsic factor contributing to this variation (Holland et al. 2002). If partners are rare, increasing abundance of one should increase benefits to the other, with the potential for a corresponding increase in population size (Stanton 2003). Ultimately, however, extrinsic limits to this response should cause returns from the interaction to saturate and even decline (e.g., Bronstein 1994, 2001). Studies demonstrating the importance of partner abundance for costs and benefits of mutualism have been limited in generality for two reasons. In most, the presence/absence manipulations used cannot characterize the full, potentially nonlinear, range of possible responses (e.g., Breton and Addicott 1992, Morales 2000). Additionally, a historical focus on partners with tightly and obligately linked life cycles excludes more generalized and common interactions (e.g., Pellmyr and Huth 1994, Anderson and Midgley 2007). These conditions simplify predictions and experimental design, but most mutualisms are more generalized. As of yet,

Manuscript received 14 July 2011; revised 13 January 2012; accepted 27 January 2012; final version received 18 February 2012. Corresponding Editor: R. E. Irwin.

${ }^{3}$ E-mail: geibjc@appstate.edu few studies have tested density dependence over a range of partner density in facultative, multispecies mutualisms.

Facultative mutualisms are common in nature (Holland and Fleming 2002, Stanton 2003) and range from highly specialized interactions, dependent on one or a few closely related partners, to broadly generalized relationships, involving multiple unrelated, but highly substitutable partner species (Bascompte et al. 2003, Thompson 2006). Generalized interactions are more ecologically complex than specialized ones, due to competition and functional redundancy among possible partners. Pollination mutualisms, which often comprise multispecies guilds on either side of the interaction (Stanton 2003), exemplify this complexity. For example, Holland and Fleming (2002) show that the availability of co-pollinating bees can influence the dynamics of interactions between senita cacti and their primary moth pollinators. Although studies of ecological networks suggest that potential partners in pollination assemblages are highly substitutable and generalized, much less is known about how generalization affects the population dynamics of the interacting species. A major goal of our study was to address this gap by comparing responses to pollinator abundance between closely related host-plant species that differ in exploitation of co-pollinator taxa.

One challenge in comparisons of specialist and generalist life histories is that niche breadth is not static over an organism's life time. A plant species' pollination 
niche can vary over a short time scale due to seasonal schedules of pollinator emergence. Olesen et al. (2008) show that temporal dynamics of pollinator assemblages vary annually as well as seasonally and that network linkages increase, indicating expanding pollination niche breadth with flowering span. We take advantage of such seasonal trends in co-pollinator availability to compare effects of pollinator density on early- (specialist) vs. late(generalist) flowering cohorts.

Impacts of pollinator abundance on plant population growth depend on the strength of causal linkages between pollinator density, pollination services, and host-plant demography (Appendix A: Fig. A1). If these linkages are stronger for specialists than generalists, increased pollinator abundance should confer greater benefits to a specialist host plant (Bronstein 1994). However, even for a specialist, successive benefits in the pathway from partner density to host recruitment may attenuate due to noise from external abiotic and biotic factors (Polis and Strong 1996, McCann et al. 1998, Gruner 2004). Studies using hand-pollination as a proxy for increased pollinator visits reveal widespread pollination deficiencies in diverse plant communities (Burd 1994, Kearns et al. 1998, Mayfield 1998, Thomson 2001, Knight et al. 2005), suggesting that increased pollinator abundance may enhance population growth in this manner. Similarly, pollinator density correlates with seed quantity (Plowright and Hartling 1981, Geib 2010), and host population declines correlate with loss of pollinator species (Biesmeijer et al. 2006). However, little evidence directly links pollinator density to plant population growth.

Moreover, there is a particular dearth of knowledge concerning effects of pollinator density on life stages beyond fecundity. Yet, if pollinators alter their foraging behavior as density increases by adding floral resources of lower rank, then changes in mating patterns within populations and potential costs of heterospecific pollen transfer may ensue. Effects on outcrossing rate, seed viability, germination timing, and offspring quality are plausible (e.g., Sobrevila 1988, Waser and Price 1989, Brock 2004, Bell et al. 2005). Changes in germination schedule and seedling establishment can impact generation time and recruitment rate (Lundemo et al. 2009) with potentially strong demographic implications. Yet post-fecundity impacts of pollinator density are largely unknown. In this study we address these gaps, examining impacts of increased pollinator density on timing and rate of seedling establishment, and creating models that link these effects to population persistence.

This study addresses the impact of partner density in facultative mutualisms using a small alpine pollination web, consisting of two native clovers, Trifolium dasyphyllum and T. parryi and a shared native bumble bee pollinator, Bombus balteatus. We experimentally vary the abundance of the pollinator in order to trace the impacts on sequential steps in the pathway from pollinator density to plant population growth (Appen- dix A: Fig. A1). This pollination network includes a copollinator, B. sylvicola, for T. dasyphyllum (Macior 1974, Byron 1980) and late-season increases in solitary bees, flies, and worker bumble bees for both clovers (Geib 2010). Thus, this plant-pollinator system is characterized by features of broader pollination networks: potential redundancy or substitutability of alternative mutualist partners and potential competition within the pollinator guild (Pleasants 1980, Bascompte et al. 2003). It provides an opportunity to move beyond pair-wise studies of pollination mutualism in a relatively simple experimental system.

The primary objectives of our study were to (1) identify steps in the transition from pollinator visitation to recruitment that depend on pollinator density, (2) determine how variation in pollination niche breadth affects plant functional response to density of a primary pollinator, and (3) use data on functional response to model population growth rate $(\lambda)$ over a range of pollinator density for specialized and generalized host species.

\section{Methods \\ Study system}

Trifolium dasyphyllum and T. parryi (Fabaceae, subfamily Faboideae) are closely related native clovers (Ellison et al. 2006), abundant in the central Rocky Mountains (USA) from treeline upward. On Pennsylvania Mountain (Park County, Colorado; see Plate 1), where our study was conducted, they flower prolifically from snowmelt in June to late August. Plants of both clovers are perennial and lack clonal spread (Weber and Wittmann 2001). T. dasyphyllum has a cushion-like growth habit averaging about eight inflorescences (heads) per plant, whereas plants of $T$. parryi produce one to two heads. The two species have similar flower longevity, with individual heads opening for 3-6 days depending on microclimate and soil moisture. $T$. dasyphyllum is more common in open dry meadows whereas $T$. parryi favors moist snowbeds. However, sympatry is common with $\sim 16 \%$ of plants found in mixed species stands (P. G. Kevan and C. Galen, unpublished data from $7520-\mathrm{m}^{2}$ plots). Fertile interspecific hybrids are rare in Trifolium (Taylor et al. 1980), and no evidence of hybridization has been found in this system. Both species are obligate outcrossers with gametophytic self-incompatibility (Dhar et al. 2006).

$T$. dasyphyllum and $T$. parryi depend mainly on Bombus for pollination (Macior 1974, Bauer 1983). T. dasyphyllum has a shorter flower tube and is extensively visited by $B$. balteatus (a long-tongued species) and $B$. sylvicola (a short-tongued species). In contrast, $T$. parryi (a longer-tubed species) is visited almost exclusively by B. balteatus. Queen bumble bees emerge in mid-June and forage throughout the summer. Workers emerge 2-3 weeks after colony establishment in early July. Solitary bees and flies also visit both clovers with increasing frequency late in the summer (Geib 2010). 


\section{Bumble bee addition experiment}

We experimentally manipulated the number of queen $B$. balteatus foraging on mixed patches of $T$. dasyphyllum and $T$. parryi. Manipulations were conducted in June-July 2007 along a south-facing ridge near treeline (3600 m elevation) on Pennsylvania Mountain (see Plate 1). Experimental patches ( $n=16: 12$ early flowering and 4 late flowering) were $2 \times 2 \mathrm{~m}$ in area and contained at least five plants of each species separated by a minimum of $20 \mathrm{~cm}$. On each of five experimental plants per species we tagged one flower head in the bud stage for intensive sampling, subject to the criteria that it contained at least 10 florets. We established this minimum size to standardize comparisons between the clovers and because very small $T$. dasyphyllum inflorescences rarely set viable seeds. However, we maintained the natural floral display of each plant (ranging from 2 to 14 heads/ plant of $T$. dasyphyllum and 1 to 2 heads/plant of $T$. parryi) by leaving other heads intact. Upon flowering, we marked the calyx of a haphazardly chosen floret on each focal inflorescence with enamel paint to assay outcross pollen receipt. To standardize plant and flower density among patches we removed inflorescences from all other plants in the plot (Trifolium and other species). The 16 patches were randomly and evenly assigned among four bumble bee addition treatments: no supplemental bumble bees (control), and one, two, or three queen $B$. balteatus added twice during flowering. The two treatment applications were conducted 48 hours apart to ensure that bees in the second round visited newly opened flowers on each experimental inflorescence.

To confine foragers within a patch, bumble bees were released individually within a temporary $2 \times 2 \mathrm{~m}$ screen enclosure (Cerf Brothers Bag Company, St. Louis, Missouri, USA) placed over the patch. Enclosures were removed after foraging bouts, leaving flowering inflorescences in all patches open to natural pollination levels. Consequently, visits to experimental inflorescences by caged $B$. balteatus were supplemental to visits by naturally foraging pollinators. By implementing $B$. balteatus addition treatments twice, 48 hours apart, during the flowering period of the experimental inflorescences we aimed to distribute additional visits relatively evenly over their 3-6 day flowering span. In this way we reduced any unintended bias in inference of density effects on fecundity that might ensue if visited flowers were the earliest or latest to open on experimental heads. Plants in control patches were uncaged and thus open throughout flowering to only natural visitors; there were no supplemental visits to control plants.

$B$. balteatus queens used for additions were caught $>500 \mathrm{~m}$ away from the patches to ensure that capturing foragers would not alter background visitation. Captured bees were held in cooled vials for transport to patches. Each was allowed to warm up and initiate foraging on a "starter" bouquet composed of a $T$. parryi and $T$. dasyphyllum inflorescence collected into a water- pik from the population surrounding experimental patches. Each bee was allowed to visit flowers on experimental plants for one foraging bout. For each bout, we recorded the sequence of inflorescence visits and the number of florets probed on each head. It was not possible to distinguish revisits to florets from initial visits. Visitation rate was calculated as the number of visits received per head divided by the total number of florets. Bouts were terminated when the bee flew to the screen tent and could not be coaxed back onto the starter. All bees were marked with non-toxic paint (Testor Corporation, Rockford, Illinois, USA) to prevent reuse before release at the original site of capture.

After flowers senesced, we collected the style from each marked floret for analysis of pollen receipt in the lab. Styles were clipped just above the ovary and preserved in 3:1 (glacial acetic acid: $95 \%$ ethanol). Mesh bags were then placed over each head to prevent seed dispersal, and plants were surrounded with plastic caging to exclude elk. In September, all infructescences were collected for seed counts. In the laboratory, outcross pollen receipt was estimated by counting stylar pollen tubes. Preparation and analysis followed Kearns and Inouye (1993). Styles were cleared in $1 \mathrm{~mol} / \mathrm{L} \mathrm{NaOH}$ for $24-26 \mathrm{~h}$ at $50^{\circ} \mathrm{C}$, then placed in a drop of $50 \%$ decolorized aniline blue in $\mathrm{K}_{3} \mathrm{PO}_{4} / 50 \%$ glycerol on a slide, and carefully squashed. A widefield epifluorescence microscope (Olympus IX70 inverted microscope, CYAN GFP filter \#31044; Olympus America, Center Valley, Pennsylvania, USA) was used to visualize pollen tubes. As self-incompatibility in Trifolium blocks pollen tube growth in the style, we assessed outcross pollen receipt by counting the number of tubes entering the lower one-third of the style. We assessed fecundity of experimental infructescences by dividing the total number of seeds produced per head by the number of florets.

\section{Impact of resources and co-pollinators on seed set}

To quantify variation in resource limitation of seed set among experimental patches and account for such heterogeneity in analysis of pollinator density effects, we supplemented pollen by hand for a haphazardly chosen inflorescence of each species within $1 \mathrm{~m}$ of each patch. Plants were left open to natural pollination. Pollen was taken from a donor located $>1 \mathrm{~m}$ from the recipient. To assess the contribution of co-pollinators to seed set we used hardware cloth cages $(0.64 \times 0.64 \mathrm{~cm}$ mesh) to exclude all $B$. balteatus queens and workers from a nearby inflorescence of each clover species. Only visitors such as flies, solitary bees, and very small Bombus workers, including potentially B. sylvicola, could move through cage openings. Fecundity was estimated as above.

\section{Recruitment}

To assess impacts of pollinator density on seedling establishment and recruitment, we collected seeds from 
bumble bee addition plots and, in October 2007, planted them into natural habitats where seedlings of each clover species were found (proven safe sites) within $100 \mathrm{~m}$ of the source populations. Seeds from early- and lateflowering plots were pooled before planting. We planted ten seed grids per species in a randomized complete block design (five blocks, two grids/species each), dividing bulked seed from each addition treatment evenly among grids. All seeds were planted after natural dispersal and before persistent winter snowfall using methods of Galen and Stanton (1999). Before planting, aboveground vegetation was trimmed and soil sieved through $1.5 \mathrm{~mm}$ mesh to about $2-3 \mathrm{~cm}$ depth to remove Trifolium seeds in the soil. Grids made of 96-cell plastic light diffuser screens were pushed $0.5 \mathrm{~cm}$ into the soil and secured to the ground with u-hooks. Within each grid, seeds from different bee density levels were randomized spatially (one seed per cell) subject to proportions determined by seed set differences among treatments. Seeds were covered with 1-2 mm of sifted soil. Germination and seedling survival were surveyed weekly from July to early August in 2008 and 2009. We assumed negligible seed germination after two years (see Appendix B).

\section{Statistical Analyses}

\section{Bumble bee addition experiment}

All statistical analyses were conducted in SAS (Version 9.1; SAS Institute 2004). We used analysis of covariance (ANCOVA; Proc MIXED) to test for relationships between (1) the number of bumble bees added (a continuous variable from 0 to 3 ) and visitation rate (i.e., visits from added bees), (2) visitation rate by added bees and pollen tubes per pistil, and (3) pollen tubes and seed set. For control patches that received no supplemental bees, bees added and visitation rates were both set at zero. Stylar pollen tubes in each flower may have resulted from visits by experimentally added bees as well as natural visitors when plants were uncaged. Data were collected from both clover species throughout the flowering period of the 16 mixed patches. However, analyses were constructed and applied to specific subsets of the full data set that best matched our experimental questions. For example, to test whether interspecific differences in pollination niche breadth affected plant responses to bumble bee density, we restricted our analysis to early-flowering patches where composition of pollinator species differs markedly between $T$. parry $i$ and $T$. dasyphyllum ( $n=12$ patches). Similarly, to explore how seasonal expansion of niche breadth within a given species affects plant responses to bumble bee density, we used only data from $T$. parryi and compared early- (specialist) and late- (generalist) flowering cohorts ( $n=12$ and 4 patches, respectively). Data from $T$. dasyphyllum were excluded since seasonal changes in niche breadth in this species were minimal. In all analyses, visitation rate, pollen tubes per pistil, and seeds per flower were square root transformed to improve homoscedasticity.

Nonlinearity in the relationship of bee density to visitation suggested a pattern of diminishing returns, so we tested for linear, quadratic, and cubic relationships. When the polynomial terms for bee abundance were significant, stepwise regression (Proc REG) was used to calculate $R^{2}$ values for all models. We then conducted $F$ tests to assess whether including the polynomial term(s) significantly increased $R^{2}$ (McDonald 2009). Patch was the experimental unit in these analyses because bee addition treatments were applied to entire patches of plants. We analyzed impacts of visitation on pollen tubes per pistil and pollen tubes on seed set with inflorescence as the experimental unit and patch as a random factor. In the analysis of fecundity, variation in resource levels among patches was accounted for by using seed production of hand-pollinated plants near each patch as an additional covariate.

\section{Impact of resources and co-pollinators on seed set}

ANOVA (Proc GLM) was used to assess the effects of resources and co-pollinators on seed set. Pollination treatment (open-pollinated, hand-pollinated, and caged), flowering time (early and late), plant species, and their interactions were fixed effects in the model (for each clover species: $n=15$ early, 5 late open-pollinated plants; $n=12$ early, 4 late hand-pollinated plants; and 12 early, 4 late caged plants).

\section{Recruitment}

Effects of bumble bee density on total seed germination rate and seedling survival after two years were tested with ANOVA (Proc GLM). We then used a repeated-measures analysis of variance (RMANOVA; Proc GLM) to test whether bumble bee augmentation affected timing of germination. For this analysis, bumble bee addition treatment ( $0-3)$ and plant species were fixed effects and the number of seeds germinating yearly the dependent variable. To ask whether bumble bee density altered plant life history schedule we used paired $t$ tests to compare the mean proportion of seeds in each grid germinating in 2008 vs. 2009 for each plant species and treatment group separately. All germination rates were arcsine-square-root-transformed before analysis. Block ( $n=5$, each containing two seed grids per species) was the experimental unit in all analyses.

\section{Matrix Model}

To probe how impacts of bumble bee density on individual performance translate into population dynamics, we developed stage-based projection matrices for each species as described in Caswell (2001) and Morris and Doak (2002). The models were based on an annual time step and utilized a pre-breeding census reflective of a birth-pulse population. Plant life histories were modeled with mixed age/stage classification (sensu Midgley et al. 2010; see Appendix B). Vital rates in the 
matrices were based on surveys we conducted or unpublished data specific to $T$. dasyphyllum and $T$. parryi when possible. Where no data were available, (e.g., for age at first flowering) we used data reported in the literature for co-occurring alpine plant species with similar life histories. Full descriptions of the life histories and parameterization of the projection matrices are described in Appendix B. For simplicity, models ignore genetic structure within populations, seed dispersal into/ out of the population, and assume constant vital rates for each life stage except as described below. Models also assume lack of density dependent effects within each population. This is a reasonable assumption since interspersed clover populations are located along a ridge characterized by high disturbance, primarily due to burrowing mammals. New sites open up regularly.

We used "retrospective" perturbation analysis (Caswell 2000) to examine how bumble bee addition impacted plant population growth rates $(\lambda)$. Fecundity rates for each species were based on the mean perinflorescence seed number of plants in each of the four experimental groups (control and one, two, or three bees added) as calculated from patch means after least squares mean adjustment to take environmental effects on seed set into account (see Statistical analysis: Bumble bee addition experiment). As least squares means adjustments to seed set were done on square root transformed means, the models were run using these values and output parameters were then back-transformed. Because both early- and late-flowering patches from the addition experiment contributed to population level vital rates, model parameters affected by seed production rates $\left(F_{1,4}\right.$ and $F_{2,4} ;$ Appendix B: Table B3) represent seed set averages for each species under each treatment over the entire flowering season (see Appendix B for details). Seedling, juvenile, and adult survival transitions and stasis parameters were point estimates (means; see Appendix B), and thus uncertainties associated with these values were not accounted for in the models. Due to the pooling of seeds from early- and late-flowering cohorts before planting, we could not assess effects of temporal differences in co-pollinator abundances on population responses. All perturbation analyses were conducted using the popbio package (Stubben and Milligan 2007) in R statistical software (version 2.10.1; R Core Development Team 2009). Parametric bootstrap techniques $(n=2000)$ (Caswell 2001) were used to estimate species-specific confidence intervals for $\lambda$ under each level of bumble bee addition.

\section{RESULTS}

\section{Bumble bee addition experiment}

In early-flowering patches, increasing $B$. balteatus density tended to affect flower visitation differently in $T$. dasyphyllum and $T$. parryi (Fig. $1 \mathrm{~A}$ and D, Appendix C: Table C1, bees $\times$ species $F_{1,18}=3.05, P=0.098$ ). For $T$. parryi, visitation showed a pattern of diminishing returns, increasing sharply up to an intermediate bumble bee density then saturating (Fig. 1D; bees ${ }^{2} F_{1,9}=8.37, P$ $=0.018$ ). Including a quadratic term in the regression model significantly increased the amount of variance explained by bee density for $T$. parryi but not $T$. dasyphyllum (respectively, $R^{2}$ increased from 0.63 to $0.81 ; F_{2,9}=8.37, P=0.009$; and from 0.57 to $0.61 ; F_{2,9}=$ $0.949, P=0.42)$. $T$. dasyphyllum experienced a more gradual linear increase in flower visitation with bumble bee addition (Fig. 1A; bees $F_{1,10}=13.24, P=0.0045$ ).

In early-flowering patches, the relationship between supplemented bumble bee visitation and pollen tubes per style also differed between species (visits $\times$ species $F_{1,106}$ $=4.89, P=0.029$; Fig. $1 \mathrm{~B}$ and E, Appendix C: Table $\mathrm{C} 2)$. The number of pollen tubes per style increased with visits to $T$. parryi $\left(F_{1,23.3}=31.83, P<0.0001\right)$, but not $T$. dasyphyllum $\left(F_{1,42}=0.50, P=0.483\right)$. Increases in pollen tubes per style enhanced seed set for both clovers, suggesting that fecundity in both species was pollination limited (Fig. 1C and F, Table C3; $F_{1,100}=12.89, P=$ $0.0005)$. However, seed set of hand-pollinated plants near each patch explained a significant amount of variation in average seed set of experimental inflorescences $\left(F_{1,24.5}=9.55, P=0.005\right)$, indicating that among patch variation in resources also affected fecundity.

B. balteatus abundance had similar positive impacts on visitation rate to $T$. parryi inflorescences early and late in the flowering season (Fig. 1D and G, Appendix C: Table C1; bees $\left.F_{1,10}=8.55, P=0.015\right)$. However, the relationship between $B$. balteatus visitation rate and pollen tubes per pistil disappeared late in the season after worker bees emerged and non-Bombus visitors increased (visits $\times$ time $F_{1,21.3}=15.52, P=0.0007$; Fig. $1 \mathrm{E}$ and $\mathrm{H}$, Table C2). Similarly, the relationship between pollination and fecundity for $T$. parryi declined in importance over the season (pollination $\times$ time $F_{1,65.3}$ $=4.62, P=0.035$; Fig. $1 \mathrm{~F}$ and I, Table C3). Late in the season only among-patch variation in resources (represented by the seed set of the adjacent hand-pollinated individuals) explained a significant proportion of the variance in seed set for $T$. parryi (HP seeds $F_{1,2.45}=18.5$, $P=0.034$; Table C3).

\section{Impact of resources and co-pollinators on seed set}

The impact of resources and co-pollinators on seed set (Fig. 2, Appendix C: Table C4) differed over the flowering season (pollination treatment $\times$ time $F_{2,91}=$ 5.21, $P=0.007$ ) for both clover species (pollination treatment $\times$ time $\times$ species $F_{2,91}=0.28, P=0.733$ ). Resource limitation of seed set increased over time; early in the season, hand-pollinated plants had greater fecundity than open-pollinated plants (a priori comparison, $P=0.0007$ ), but late in the season seed set did not differ between hand-pollinated and open-pollinated plants (a priori comparison, $P=0.332$ ).

The contribution of co-pollinators to seed set also increased over the flowering season. For early-flowering plants (prior to the emergence of worker bumble bees), co-pollinators contributed to seed set of bumble bee- 

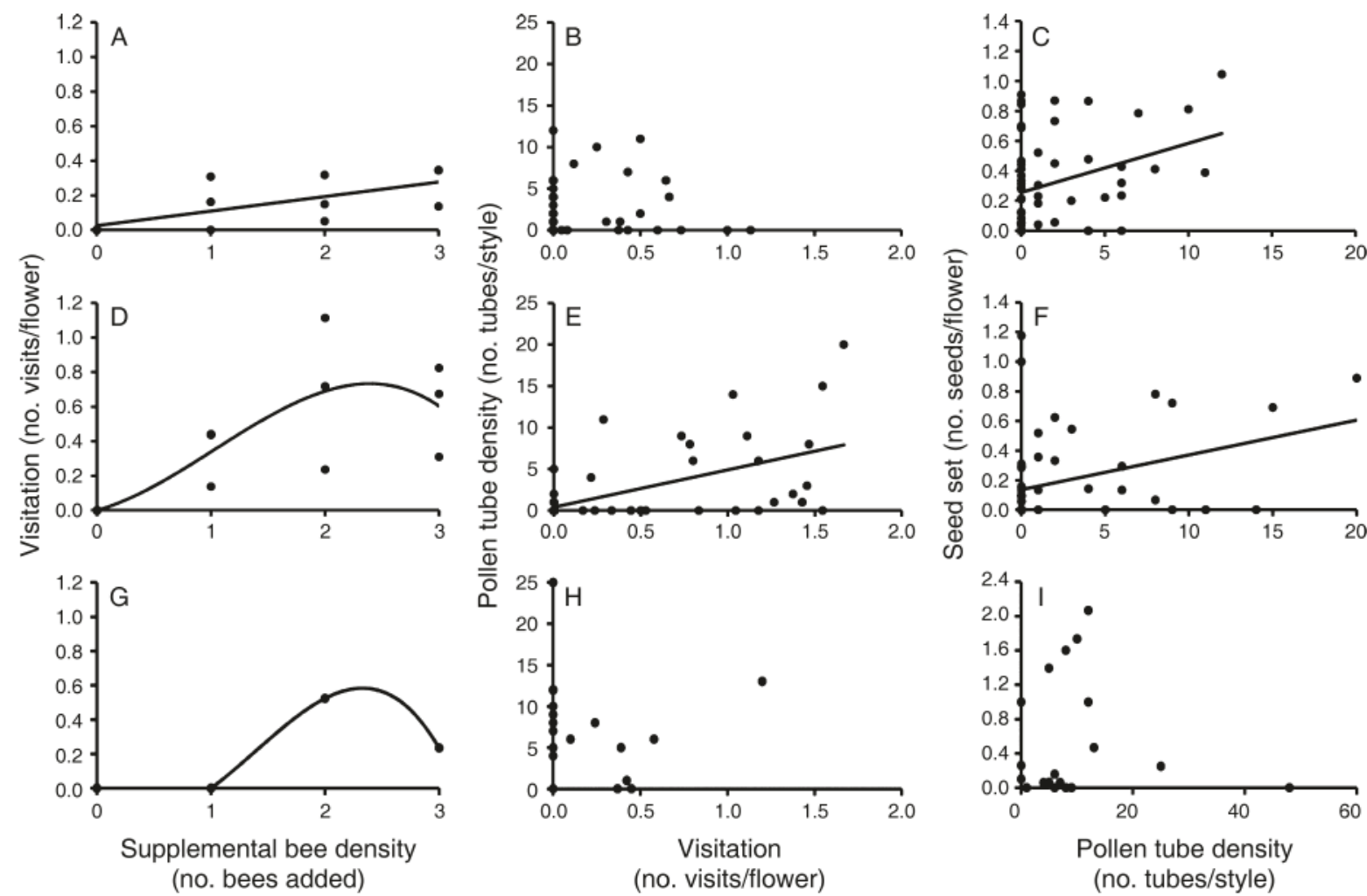

FIG. 1. Relationships between (A) supplemental bee density and visitation, (B) visitation by added bees and pollen tube density, and (C) pollen tube density and seed set for early-flowering Trifolium dasyphyllum. Panels (D)-(F) and (G)-(I) show the same relationships for early- and late-flowering $T$. parryi, respectively. Curvilinear lines represent polynomial regression. Only significant regression lines are shown.

excluded $T$. dasyphyllum plants, but not $T$. parryi (mean seed set of bumble bee-excluded plants $+95 \% \mathrm{CI}=0.112$ \pm 0.06 and $0.021 \pm 0.03$, respectively for $T$. dasyphyllum and $T$. parryi). However, both clovers set significantly more seed when bumble bees (queens only at this time) were allowed access to flowers (a priori comparison, bumble-bee-excluded vs. open-pollinated, $P=0.0066$ ). Conversely, for both species seed set increased late in the season after emergence of worker bumble bees independent of exclusion treatment (a priori comparison, $P=$ 0.296).

\section{Recruitment}

Seed germination rate depended on bumble bee addition treatment in both clovers. For $T$. dasyphyllum germination was lowest in patches augmented with three bees (planned contrast, $F_{1,24}=52.89, P<0.0001$; Fig. 3B, Appendix C: Table C5). T. parryi seeds from patches augmented with $B$. balteatus exhibited higher germination than seeds from control patches (planned contrast $F_{1,24}=62.01, P<0.0001$; Fig. 3A, Table C5).

$B$. balteatus addition tended to affect seed germination schedules in a species-specific manner (RMANOVA, time $\times$ species $\times$ bees $F_{3,32}=2.46, P=0.081$; Appendix C: Table C6). For T. dasyphyllum (Fig. 3C), seeds from most patches were equally likely to germinate in 2008 or 2009 (paired $t$ tests comparing germination each year for 0,2 , and 3 bees added, respectively: $t_{4}=$ $-0.595, t_{4}=0.426, t_{3}=0 ; P>0.50$ for all). However

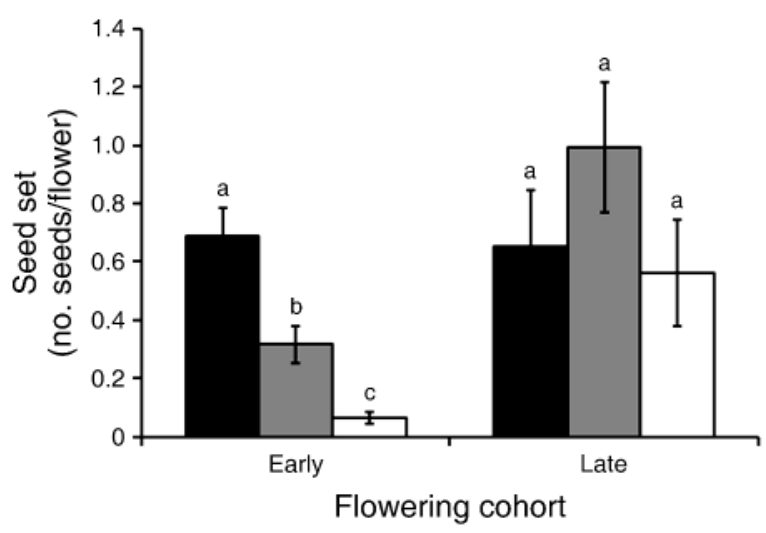

FIG. 2. Seed set for Trifolium plants receiving supplemental outcross pollen (black bars), screened from Bombus balteatus (white bars), or naturally pollinated controls (gray bars). The species are pooled because differences between them were not statistically significant. Within each time of season, treatments with different lowercase letters are significantly different at $P<$ 0.05 . Error bars show $\pm \mathrm{SE}$. 


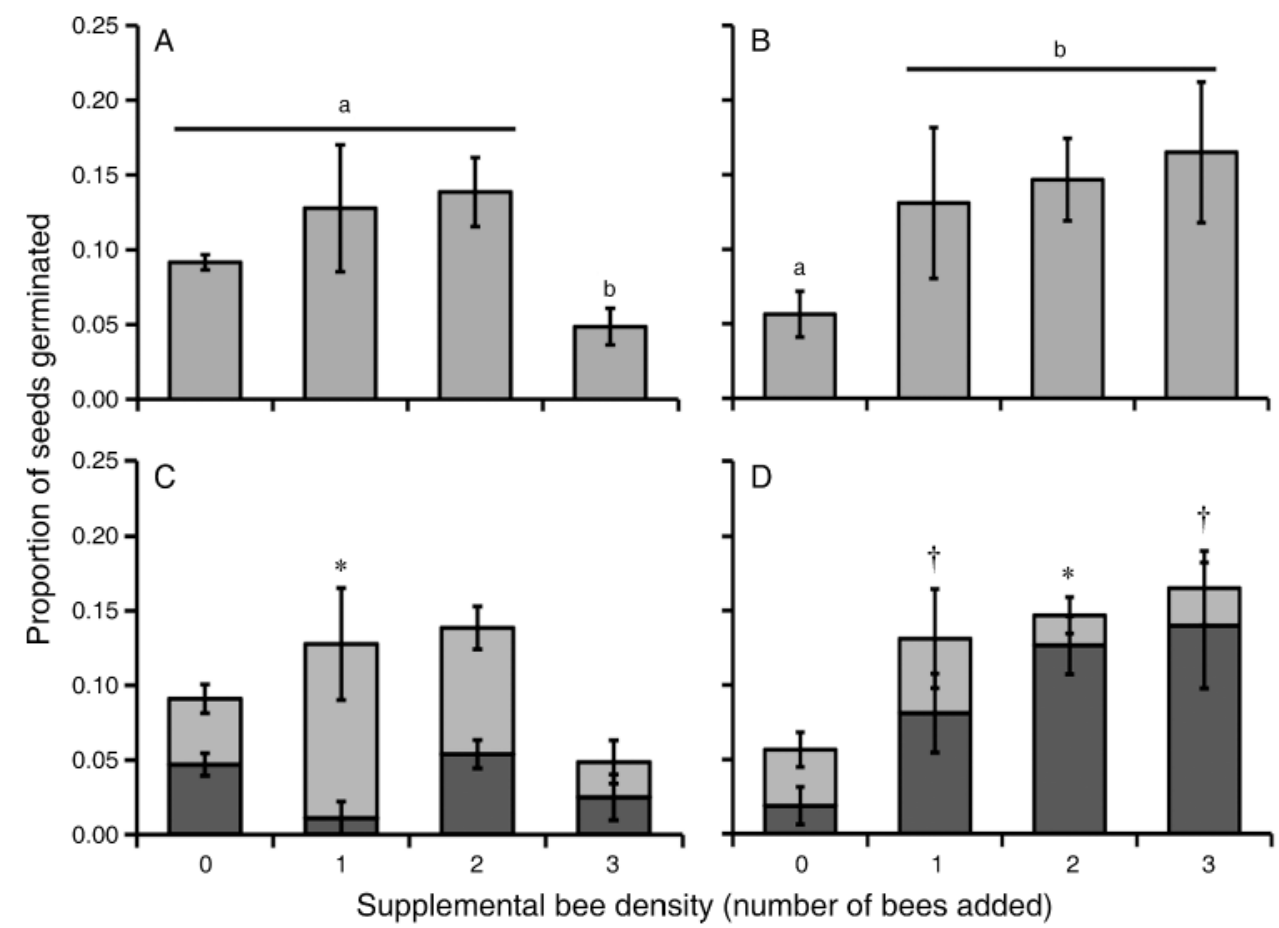

FIG. 3. The effects of $B$. balteatus abundance on seed germination rate and timing. Comparisons of total germination rate (pooled over years) among bumble bee addition groups are shown for (A) $T$. dasyphyllum and (B) $T$. parryi. Treatments with different lowercase letters are significantly different at $P<0.05$. Comparisons of germination rates in 2008 and 2009 among bumble bee addition groups are shown for (C) $T$. dasyphyllum and (D) $T$. parryi. Within each treatment group, black and gray sections show relative contribution to total germination from 2008 and 2009 , respectively. A dagger indicates a trend for differences in germination rate between years at $P<0.10$, and asterisks indicates significant differences between years at $P<0.05$. Error bars show \pm SE.

seeds from patches receiving one extra $B$. balteatus exhibited higher germination in 2009, the second year after planting $\left(t_{3}=5.00, P=0.015\right)$. For $T$. parryi (Fig. 3D), seeds from bee addition patches tended to germinate earlier (in 2008, the first year after planting; with 1,2 , or 3 bees added, respectively, $t_{3}=-2.33, P=$ $\left.0.10 ; t_{4}=-5.11, P=0.0069 ; t_{3}=-3.00, P=0.058\right)$, whereas seeds from control patches were equally likely to germinate in 2008 and $2009\left(t_{3}=1.21, P=0.31\right)$. There were no differences in seedling survival among treatment groups $\left(F_{19,23}=0.83, P=0.658\right.$; Table C7 $)$.

\section{Matrix model}

B. balteatus density had no consistent impact on $T$. dasyphyllum population growth, as $\lambda$ oscillated in a nonlinear manner with bee density (Fig. 4A). For $T$. parryi, $\lambda$ tended to increase under all three addition treatments compared to the control, however overlapping confidence intervals show this trend is not significant (Fig. 4B).

\section{Discussion}

We found that Trifolium parryi and $T$. dasyphyllum differ in functional responses to changes in abundance of Bombus balteatus, a shared primary pollinator. For early-flowering $T$. parryi, benefits of bumble bee addition were manifest in flower visitation, pollination, and fecundity. In contrast, for $T$. dasyphyllum, bumble bee addition enhanced visitation, but attenuated in impact on sequential transitions. Moreover, the shape of the benefits curve differed between species, with diminishing returns in visitation for $T$. parryi and gradual linear returns for $T$. dasyphyllum. At the population level, $\lambda$ for $T$. dasyphyllum fluctuated independently of $B$. balteatus density, while $\lambda$ for $T$. parryi showed a modest positive trend with supplementation of $B$. balteatus. Some but not all of these findings align with expectations based on pollination niche breadth.

\section{Individual-level effects}

The cascade of effects from increasing pollinator abundance to seed set varied with interspecific and intraseasonal differences in pollination niche breadth between $T$. parryi and $T$. dasyphyllum. Specifically, for the more specialized host plant, T. parryi, B. balteatus visitation peaked rapidly and saturated at an intermediate density, supporting a model of diminishing returns and concurring with predictions for benefit accrual curves developed for obligate pair-wise interactions 


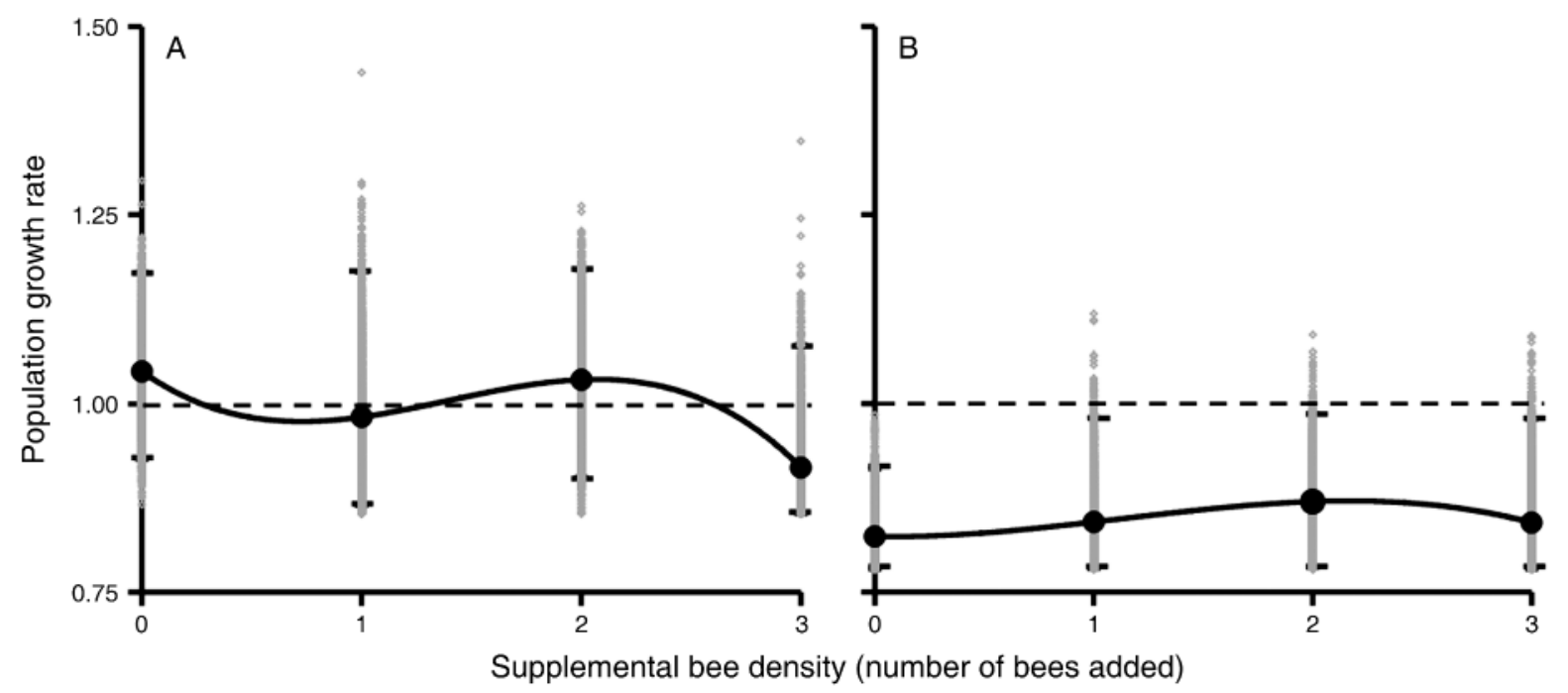

FIG. 4. Mean population growth rates ( $\lambda$ ) with $95 \%$ confidence intervals for (A) T. dasyphyllum and (B) T. parryi.

(Bronstein 2001) and recently extended to more generalized pollination mutualisms (Morris et al. 2010). For the generalist, T. dasyphyllum, visitation accrued gradually with increased bee density and a satiation threshold was not reached. Mutualism theory predicts increases in individual benefits as partners increase followed by satiating or diminishing returns at the highest partner density as other biotic and abiotic factors limit individuals' ability to respond (Stanton 2003). Notably, we likely would not have seen this trend had we estimated benefit response curves from single species patches. As bee density increased and nectar resources were exhausted in $T$. parryi, individual foragers shifted their diet to include a greater proportion of flower visits to T. dasyphyllum (Appendix A: Fig. A2). The propensity for bees to expand their diet breadth in a density dependent manner has been reported in other studies (Fontaine et al. 2008), and is not surprising given their capacity to discriminate among flowers based on visitation history (Heinrich 1979). Our results suggest that host switching at high pollinator density is likely to be a common mechanism for diminishing returns in flower visitation by facultative mutualists. Young and Young (1992) proposed a number of other mechanisms promoting diminishing returns in single species stands including pollen tube crowding, pollen removal or stigma damage from excess visitation, and deposition of inviable pollen.

We predicted that the relationship between visitation of $B$. balteatus and pollen deposition/ovule fertilization rates in both clover species would vary with copollinator abundance. Hand-pollinations early in the season enhanced seed set, demonstrating pollination limitation. However, after co-pollinators emerged, seed set in both clovers was likely limited by resources (or some other unmeasured factor) since it was unrelated to pollen tube density and unaffected by pollen supplementation. Flies, solitary bees, and potentially worker bees of B. balteatus and B. sylvicola effectively pollinated $T$. dasyphyllum throughout the summer. Accordingly, the modest density-dependent increase in flower visitation by $B$. balteatus attenuated with little fitness impact. Similarly, for plants of $T$. parryi flowering late in the summer, loss of sensitivity to B. balteatus density is consistent with a co-pollinator effect. Late-flowering mixed clover patches were more limited in number at our study site, tempering conclusions about seasonal shifts in pollination niche breadth. Because cohort comparisons were made between patches, spatial and temporal differences in confounding factors affecting seed set are possible. However, all patches were located on the same ridge (total area approximately $100 \times 30 \mathrm{~m}$ ) minimizing large-scale environmental heterogeneity. Additionally, we aimed to account for possible temporal variation in environmental effects on fecundity (rainfall, temperature), by using seed set of co-flowering hand-pollinated neighbors to each patch as a covariate in the analysis. Overall, the finding that strikingly similar relationships between pollinator density and visitation translated into different reproductive benefits for early- and late-flowering $T$. parryi is consistent with the view that co-pollinators reduce the dependency of late-flowering plants on specialist partners. Our study adds to a number of others (Holland and Fleming 2002, Miller 2007, Bosch et al. 2009) documenting temporal changes in partner specialization within mutualisms (pollination and others, including cacti and cactustending ants) and emphasizing the importance of monitoring interaction webs throughout the reproductive season and over multiple years (see also Petanidou et al. 2008, Burkle and Irwin 2009, Morales 2011). 


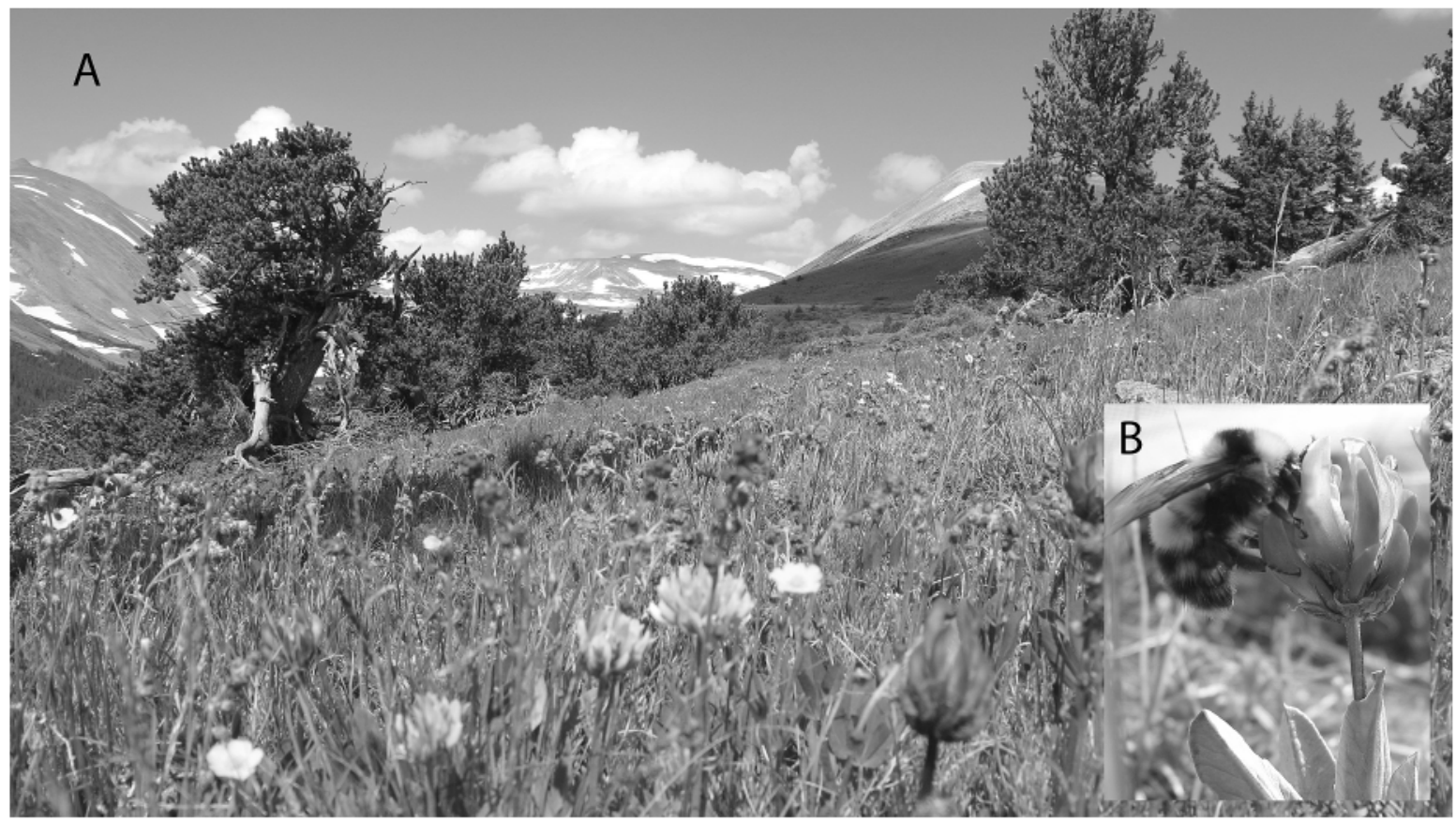

Plate 1. Study site and system: (A) Mixed patch of Trifolium dasyphyllum and T. parryi (foreground) along the south-facing ridge of Pennsylvania Mountain, Park County, Colorado, USA, (elevation 3600 m); (B) Bombus balteatus queen foraging on T. parryi. Photo credit: J. C. Geib.

\section{Effects on stages linking individual fitness and population growth}

Morris et al. (2010) make predictions about recruitment rates in three typical pollination mutualisms based on plant fitness responses to pollinator density. However, our results revealed additional linkages between pollinator density and recruitment. Specifically, bumble bee density not only affected offspring quantity but unexpectedly altered seed fate after dispersal. Pollinator addition increased $T$. parryi recruitment via enhanced germination rate and advanced germination timing. Seeds produced from patches with two or more $B$. balteatus germinated more often and earlier than seeds from open-pollinated plants. Conversely, for $T$. dasyphyllum bumble bee addition had more variable and occasionally negative effects, reducing seed germination when three bees were added and delaying germination with one bee added.

Pollinator effects on seed germination and dormancy likely represent paternal effects, or maternal-by-paternal interaction. Seed germination is sensitive to genetic compatibility between pollen and ovules (Sobrevila 1988, Waser and Price 1989), environmental conditions of the pollen parent (Galloway 2001), and deposition of heterospecific pollen (Murphy 2000, Brock 2004). Although our study was not designed to reveal underlying mechanisms, positive impacts of bumble bee density on $T$. parryi germination may be due to outcross advantage or increased opportunities for female choice (Marshall and Folsom 1991). Conversely, preference of $B$. balteatus for $T$. parryi may have increased heterospecific pollen transfer to $T$. dasyphyllum with negative impacts on offspring quality. Deposition of heterospecific pollen can break down selfincompatibility mechanisms, reducing offspring fitness in highly outcrossing species (e.g., mentor effect; Brock 2004). In patches receiving two B. balteatus queens, bumble bees rarely visited $T$. dasyphyllum (Fig. A2), and $T$. dasyphyllum seeds likely resulted from co-pollinators that avoided $T$. parryi. Compatibility mechanisms may also explain effects of bee addition on seed dormancy schedule. Embryos of different quality vary in requirements for breaking dormancy (e.g., García-Gusano et al. 2005) and maternal by paternal interaction effects alter germination timing in other species (Snow 1990). Dormancy in some clovers is sensitive to embryo genetics (e.g., T. subterraneum L., Morley 1958). While effects of pollinator density on seed size are known (Steffan-Dewenter 2003), this is the first study to document the effects of pollinator abundance on seed germination and dormancy. It seems likely that these kinds of effects are widespread in facultative pollination mutualisms, because the key features of our experiments (mixed species stands, pollinator sharing, and patchy spatial distributions) are common in nature. Depending on the relative importance of recruitment in the life history of plant species, pollinator visitation effects on seed germination rates and timing (genetic impacts) could alter host-plant population dynamics in ways that reinforce demographic effects of pollinators on seed 
production (ecological impacts). Unfortunately, the prebreeding model structure we used precluded evaluating the relative contributions to $\lambda$ of pollinator density effects on seed production vs. germination. However, these questions should provide highly fruitful directions for future research.

Any behavioral experiment runs the risk of altering subject response relative to norms in natural environments. In the present study, use of artificial arenas to manipulate bee density may have unintentionally altered pollen flow patterns among focal plants. Observations of naturally foraging $B$. balteatus in open mixed clover patches concurrent to this study indicate that, in both open habitats and enclosures, bees have strong preference for and fidelity to $T$. parryi compared to $T$. dasyphyllum (Geib 2010). Bees were more likely to move from $T$. parryi to $T$. dasyphyllum in enclosures than in the field ( $13 \%$ vs. $5.2 \%$ of all transitions; Geib 2010$)$, but inter-plant flight distances exhibited similar ranges in both contexts (2.5-156.3 cm in enclosures and 1-198 cm in the field). These data suggest putative costs to experimental plants of $T$. dasyphyllum from heterospecific pollen receipt might be somewhat higher than in nature, but chance of mating among relatives would not have been altered in the experimental arrays. Overall, because we chose to leave plants in place in their native habitats and allow for intervals of natural pollination during their flowering spans, our experiments likely introduced more modest artifacts for plant reproduction and gene flow than other more common designs for pollinator manipulation, including potting and transportation to the laboratory or screen house.

Mutualisms are thought to evolve in ways that limit benefits to any one species from increasing partner abundance, ensuring the stability of the interaction (Holland et al. 2004). Reduction of benefits and/or increased costs at high partner abundances have been observed in pair-wise obligate mutualisms (Pellmyr and Huth 1994, Herre and West 1997, Anderson and Midgley 2007). A few studies have also demonstrated patterns of diminishing returns in facultative interactions. A review of mycorrhizal colonization and benefits to plants showed benefits maximizing at an intermediate colonization rate (Gange and Ayres 1999). Two studies of antplant interactions (Ness et al. 2006, Holland et al. 2011) observed saturation in benefits at high partner density. Morris et al. (2010) show saturating or diminished pollination and seed set at high pollinator visitation in facultative pollination mutualism. Here we have demonstrated reduced benefits and increased costs during multiple life history stages at high partner density.

\section{Population effects}

Do benefits to individual plants from increased pollinator abundance translate to growth at the population level? Our results suggest that such linkages may be weak, even for relatively specialized plant species. For plants that exploit broad assemblages of co-pollinators, population dynamics are unlikely to depend on density of any one species. T. dasyphyllum fits this scenario. However, in populations of more specialized $T$. parryi, we expected that diminishing returns with increased $B$. balteatus density at the individual level would impact growth rate $(\lambda)$. Nonetheless, we observed a relatively modest non-significant tendency for populations to benefit from bee additions. Pollinator density impacts on $T$. parryi seed production and germination occur at very early stages in the life history of this long-lived species. Our results suggest that population dynamics for alpine clover are likely to depend more on the capacity of adult life stages to tolerate environmental challenges than on seedling establishment (e.g., Forbis and Doak 2004, Weppler et al. 2006).

The robust demographic data required to accurately assess ecological interaction impacts on population dynamics is a rare commodity for long-lived plant species living in extreme environments. Yet, such species are precisely the organisms for which such data are most needed, as they may be among the first threatened by anthropogenic climactic changes (Parmesan 2006). Although pollinator density did not exhibit strong demographic impacts for alpine clover populations in our study, co-declines of linked plant and pollinator populations (Biesmeijer et al. 2006) provide hints that demographic impacts are possible. Moreover, the need to colonize new locales as montane species shift ranges upward (a well-documented phenomenon [Grabherr et al. 1994, Pauli et al. 1996, Luckman and Kavanagh 2000]), could increase the importance of seed production and germination in alpine species, making their demographics more dependent on pollinators. Further studies of the population-level consequences of variation in pollinator abundance are urgently needed in a wider array of species and habitats to inform predictions about variations in pollinator density and its impact on pollination services to affected plants.

\section{ACKNOWLEDGMENTS}

We thank R. Holdo, K. M. Becklin, A. Michels, M. Osbourn, and two anonymous reviewers for insightful comments on the manuscript. R. Holdo and C. Stubbins advised on coding in R statistical software. P. Marting, M. Pallo, A. Evers, and D. Marsky assisted in the field and the lab. Funding for this research came from NSF Grants DEB-0709833 to J. Geib and DEB-0316110 to C. Galen, and from the American Alpine Club. We are grateful to R. Greinitz and the USFS for access to field sites on Pennsylvania Mountain.

\section{Literature Cited}

Anderson, B., and J. Midgley. 2007. Density-dependent outcomes in a digestive mutualism between carnivorous Roridula plants and their associated hemipterans. Oecologia 152:115-120.

Bascompte, J., P. Jordano, C. Melian, and J. Olesen. 2003. The nested assembly of plant-animal mutualistic networks. Proceedings of the National Academy of Sciences USA 100:9383-9387.

Bauer, P. J. 1983. Bumblebee pollination relationships on the Beartooth Plateau tundra of southern Montana. American Journal of Botany 70:134-144. 
Bell, J. M., J. D. Karron, and R. J. Mitchell. 2005. Interspecific competition for pollination lowers seed production and outcrossing in Mimulus ringens. Ecology 86:762-771.

Biesmeijer, J. C., S. P. M. Roberts, M. Reemer, R. Ohlemuller, M. Edwards, T. Peeters, A. P. Schaffers, S. G. Potts, R. Kleukers, C. D. Thomas, J. Settele, and W. E. Kunin. 2006. Parallel declines in pollinators and insect-pollinated plants in Britain and the Netherlands. Science 313:351-354.

Bosch, J., A. M. Martín González, A. Rodrigo, and D. Navarro. 2009. Plant-pollinator networks: adding the pollinator's perspective. Ecology Letters 12:409-419.

Breton, L. M., and J. F. Addicott. 1992. Density-dependent mutualism in an aphid-ant interaction. Ecology 73:21752180.

Brock, M. T. 2004. The potential for genetic assimilation of a native dandelion species, Taraxacum ceratophorum (Asteraceae), by the exotic congener T. officinale. American Journal of Botany 91:656-663.

Bronstein, J. L. 1994. Conditional outcomes in mutualistic interactions. Trends in Ecology and Evolution 9:214-217.

Bronstein, J. L. 2001. The costs of mutualism. American Zoologist 41:825-839.

Burd, M. 1994. Bateman's principle and plant reproduction: the role of pollen limitation in fruit and seed set. Botanical Review 60:83-139.

Burkle, L., and R. Irwin. 2009. The importance of interannual variation and bottom-up nitrogen enrichment for plantpollinator networks. Oikos 118:1816-1829.

Byron, P. A. 1980. On the systematics of Coloradan bumblebees. Dissertation. University of Colorado, Boulder, Colorado, USA.

Caswell, H. 2000. Prospective and retrospective perturbation analyses: their roles in conservation biology. Ecology 81:619627.

Caswell, H. 2001. Matrix population models: construction, analysis, and interpretation. Second edition. Sinauer, Sunderland, Massachusetts, USA.

Dhar, R., N. Sharma, and B. Sharma. 2006. Ovule abortion in relation to breeding system in four Trifolium species. Current Science 91:482-485.

Ellison, N. W., A. Liston, J. J. Steiner, W. M. Williams, and N. L. Taylor. 2006. Molecular phylogenetics of the clover genus (Trifolium-Leguminosae). Molecular Phylogenetics and Evolution 39:688-705.

Fontaine, C., C. L. Collin, and I. Dajoz. 2008. Generalist foraging of pollinators: diet expansion at high density. Journal of Ecology 96:1002-1010.

Forbis, T. A., and D. F. Doak. 2004. Seedling establishment and life history trade-offs in alpine plants. American Journal of Botany 91:1147-1153.

Galen, C., and M. L. Stanton. 1999. Seedling establishment in alpine buttercups under experimental manipulations of growing-season length. Ecology 80:2033-2044.

Galloway, L. F. 2001. The effect of maternal and paternal environments on seed characters in the herbaceous plant Campanula americana (Campanulaceae). American Journal of Botany 88:832-840.

Gange, A. C., and R. L. Ayres. 1999. On the relation between arbuscular mycorrhizal colonization and plant "benefit." Oikos 87:615-621.

García-Gusano, M., P. Martínez-Gómez, and F. Dicenta. 2005. Pollinizer influence on almond seed dormancy. Scientia Horticulturae 104:91-99.

Geib, J. C. 2010. The impact of pollinator abundance on benefits from facultative pollination mutualism. University of Missouri, Columbia, Missouri, USA.

Grabherr, G., M. Gottfried, and H. Pauli. 1994. Climate effects on mountain plants. Nature 369:448.

Gruner, D. S. 2004. Attenuation of top-down and bottom-up forces in a complex terrestrial community. Ecology 85:30103022.
Heinrich, B. 1979. Bumblebee economics. Harvard University Press, Cambridge, Massachusetts, USA.

Herre, E. A., and S. A. West. 1997. Conflict of interest in a mutualism: documenting the elusive fig wasp-seed trade-off. Proceedings: Biological Sciences 264:1501-1507.

Holland, J. N., S. A. Chamberlain, and T. E. X. Miller. 2011. Consequences of ants and extrafloral nectar for a pollinating seed-consuming mutualism: ant satiation, floral distraction or plant defense? Oikos 120:381-388.

Holland, J. N., D. L. DeAngelis, and J. L. Bronstein. 2002. Population dynamics and mutualism: functional responses of benefits and costs. American Naturalist 159:231-244.

Holland, J. N., D. L. DeAngelis, and S. T. Schultz. 2004. Evolutionary stability of mutualism: interspecific population regulation as an evolutionarily stable strategy. Proceedings of the Royal Society B 271:1807-1814.

Holland, J. N., and T. H. Fleming. 2002. Co-pollinators and specialization in the pollinating seed-consumer mutualism between senita cacti and senita moths. Oecologia 133:534540 .

Kearns, C. A., and D. W. Inouye. 1993. Techniques for pollination biologists. University Press of Colorado, Niwot, Colorado, USA.

Kearns, C. A., D. W. Inouye, and N. M. Waser. 1998. Endangered mutualisms: the conservation of plant-pollinator interactions. Annual Review of Ecology and Systematics 29:83-112.

Knight, T. M., J. A. Steets, J. C. Vamosi, S. J. Mazer, M. Burd, D. R. Campbell, M. R. Dudash, M. O. Johnston, R. J. Mitchell, and T.-L. Ashman. 2005. Pollen limitation of plant reproduction: pattern and process. Annual Review of Ecology, Evolution, and Systematics 36:467-497.

Luckman, B., and T. Kavanagh. 2000. Impact of climate fluctuations on mountain environments in the Canadian Rockies. Ambio 29:371-80.

Lundemo, S., M. Falahati-Anbaran, and H. K. Stenoien. 2009. Seed banks cause elevated generation times and effective population sizes of Arabidopsis thaliana in northern Europe. Molecular Ecology 18:2798-2811.

Macior, L. W. 1974. Pollination ecology of the front range of the Colorado Rocky Mountains. Melanderia 15:1-59.

Marshall, D. L., and M. W. Folsom. 1991. Mate choice in plants: an anatomical to population perspective. Annual Review of Ecology and Systematics 22:37-63.

Mayfield, M. M. 1998. Shortcomings of current crop pollination strategies: lessons from natural pollination systems. Thesis. Reed College, Portland, Oregon, USA.

McCann, K., A. Hastings, and G. R. Huxel. 1998. Weak trophic interactions and the balance of nature. Nature 395:794-798.

McDonald, J. H. 2009. Handbook of biological statistics. Second edition. Sparky House Publishing, Baltimore, Maryland, USA.

Midgley, G. F., I. D. Davies, C. H. Albert, R. Altwegg, L. Hannah, G. O. Hughes, L. R. O'Halloran, C. Seo, J. H. Thorne, and W. Thuiller. 2010. BioMove - an integrated platform simulating the dynamic response of species to environmental change. Ecography 33:612-616.

Miller, T. E. X. 2007. Does having multiple partners weaken the benefits of facultative mutualism? A test with cacti and cactus-tending ants. Oikos 116:500-512.

Morales, M. A. 2000. Mechanisms and density dependence of benefit in an ant-membracid mutualism. Ecology 81:482489.

Morales, M. A. 2011. Model selection analysis of temporal variation in benefit for an ant-tended treehopper. Ecology 92:709-719.

Morley, F. H. W. 1958. The inheritance and ecological significance of seed dormancy in subterranean clover (Trifolium subterraneum L.). Australian Journal of Biological Sciences 11:261-274. 
Morris, W. F., and D. F. Doak. 2002. Quantitative conservation biology: theory and practice of population viability analysis. Sinauer, Sunderland, Massachusetts, USA.

Morris, W. F., D. P. Vázquez, and N. P. Chacoff. 2010. Benefit and cost curves for typical pollination mutualisms. Ecology 91:1276-1285.

Murphy, S. D. 2000. Field testing for pollen allelopathy. Journal of Chemical Ecology 26:2155-2172.

Ness, J. H., W. F. Morris, and J. L. Bronstein. 2006. Integrating quality and quantity of mutualistic service to contrast ant species protecting Fercactus wislizeni. Ecology 87:912-921.

Olesen, J. M., J. Bascompte, H. Elberling, and P. Jordano. 89:1573-1582.

Parmesan, C. 2006. Ecological and evolutionary responses to recent climate change. Annual Review of Ecology, Evolution, and Systematics 37:637-669.

Pauli, H., M. Gottfried, and G. Grabherr. 1996. Effects of climate change on mountain ecosystems: upward shifting of mountain plants. World Research Review 8:382-390.

Pellmyr, O., and C. J. Huth. 1994. Evolutionary stability of mutualism between yuccas and yucca moths. Nature $372: 257-260$.

Petanidou, T., A. S. Kallimanis, J. Tzanopoulos, S. P. Sgardelis, and J. D. Pantis. 2008. Long-term observation of a pollination network: fluctuation in species and interactions, relative invariance of network structure and implications for estimates of specialization. Ecology Letters 11:564-575.

Pleasants, J. M. 1980. Competition for bumblebee pollinators in Rocky Mountain plant communities. Ecology 61:14461459.

Plowright, R. C., and L. K. Hartling. 1981. Red clover pollination by bumble bees: a study of the dynamics of a plant-pollinator relationship. Journal of Applied Ecology

Polis, G. A., and D. R. Strong. 1996. Food web complexity and community dynamics. American Naturalist 147:813.

R Core Development Team. 2009. R version 2.10.1. R Project for Statistical Computing, Vienna, Austria. www.r-project.org 2008. Temporal dynamics in a pollination network. Ecology 18:639-647.

SAS Institute. 2004. SAS version 9.1. SAS Institute, Cary North Carolina, USA.

Snow, A. A. 1990. Effects of pollen-load size and number of donors on sporophyte fitness in wild radish (Raphanus raphanistrum). American Naturalist 136:742-758.

Sobrevila, C. 1988. Effects of distance between pollen donor and pollen recipient on fitness components in Espeletia schultzii. American Journal of Botany 75:701-724.

Stanton, M. L. 2003. Interacting guilds: Moving beyond the pairwise perspective on mutualisms. American Naturalist 162:S10-S23.

Steffan-Dewenter, I. 2003. Seed set of male-sterile and malefertile oilseed rape (Brassica napus) in relation to pollinator density. Apidologie 34:227-235.

Stubben, C. J., and B. G. Milligan. 2007. Estimating and analyzing demographic models using the popbio package in R. Journal of Statistical Software 22.

Taylor, N. L., R. F. Quarles, and M. K. Anderson. 1980. Methods of overcoming interspecific barriers in Trifolium. Euphytica 33:431-441.

Thompson, J. N. 2006. Mutualistic webs of species. Science 312:372-373.

Thomson, J. D. 2001. Using pollination deficits to infer pollinator declines: Can theory guide us? Conservation Ecology 5:6.

Waser, N. M., and M. V. Price. 1989. Optimal outcrossing in Ipomopsis aggregata: seed set and offspring fitness. Evolution 43:1097-1109.

Weber, W. A., and R. C. Wittmann. 2001. Colorado flora: Eastern Slope. Third edition. University Press of Colorado, Boulder, Colorado, USA.

Weppler, T., P. Stoll, and J. Stocklin. 2006. The relative importance of sexual and clonal reproduction for population growth in the long-lived alpine plant Geum reptans. Journal of Ecology 94:869-879.

Young, H. J., and T. P. Young. 1992. Alternative outcomes of natural and experimental high pollen loads. Ecology 73:639647.

\section{Supplemental Material}

\section{Appendix A}

Figures showing the hypothesized causal pathway through which pollinator density contributes to transitions in alpine clover life history and mean flower visits to Trifolium dasyphyllum and T. parryi under each level of Bombus balteatus density (Ecological Archives E093-141-A1).

\section{Appendix B}

Model development and parameterization of projection matrices for Trifolium dasyphyllum and T. parryi (Ecological Archives E093-141-A2).

\section{Appendix C}

Seven ANOVA and ANCOVA tables for statistical analyses discussed in Results (Ecological Archives E093-141-A3). 